\title{
LOS AUTORES COMO ACTORES EN EL TEATRO EXPERIMENTAL ESPAÑOL DE LOS AÑOS VEINTE
}

\author{
María Jesús Fraga Fernández-Cuevas \\ Universidad Complutense de Madrid
}

A Juan Aguilera Sastre

\section{RESUMEN}

En los ensayos de renovación teatral de los años veinte, varios dramaturgos intervinieron como actores. Los hermanos Baroja actuaron en la compañía 'El Mirlo Blanco': la participación de D. Pío fue entusiasta pero breve; de su hermano Ricardo se recuerda con mayor interés su labor de escenógrafo. Las numerosas actuaciones de Rivas Cherif fueron unánimemente valoradas por su coherencia con los presupuestos del nuevo teatro que tanto defendió. Eusebio de Gorbea fue el dramaturgo más reconocido en su labor de actor, si bien sus rasgos más destacados, tono, ademán, rudeza le sitúan cercano al naturalismo. La labor interpretativa de estos autores como componentes de un grupo, cuyo núcleo se mantiene en los sucesivos intentos renovadores, es también alabada por su disciplina, renuncia al lucimiento y supeditación al tratamiento escénico.

Palabras clave: Actores, dramaturgos, renovación teatral, 'El Mirlo Blanco', 'El Cántaro Roto', 'Caracol', Pío Baroja, Rivas Cherif, Eusebio de Gorbea.

\section{PLAYWRIGHTS AS ACTORS IN THE SPANISH EXPERIMENTAL THEATRE OF THE 20'S}

\begin{abstract}
During the attempts for theatrical renewal in the twenties, several playwrights worked also as actors. The Baroja's acted in the company 'El Mirlo Blanco'; D. Pío participation was enthusiastic although brief, while his brother Ricardo was better recognized for his work as stage designer. Rivas Cherif participated in numerous performances and his coherence with the new theatre model that he defended was unanimously praised. Eusebio de Gorbea was considered the best actor among the playwrights, although his more appreciated characteristics like tone, gesture and roughness approached him to naturalism. The interpretative work of these authors as components of a group, whose nucleus remained amongst successive renovation attempts, is also recognized by its discipline, renounce to individual success and subordination to scenic treatment.
\end{abstract}

Key words: Actors, Playwrights, Theatrical renewal, 'El Mirlo Blanco', 'El Cántaro Roto', 'Caracol', Pío Baroja, Rivas Cherif, Eusebio de Gorbea. 
A comienzos de los años veinte la escena española sufría una profunda crisis. En manos de empresarios poco interesados por las nuevas tendencias creativas de los autores españoles o por las novedades extranjeras, todavía se mantenían las formas del teatro de pasatiempo, burgués y comercial. Las reivindicaciones de los renovadores no se limitaban a una mayor exigencia en la calidad de los textos; incluían también la adecuación de los locales, la innovación escenográfica, la adopción de avances técnicos y la formación de actores y público. Con estos cambios, los vanguardistas de principios del XX se proponían luchar contra «lo que se entendía como una falta de inquietudes, un pensamiento estancado y la divulgación de una moral conservadora y reaccionaria» 1 .

La deficiente calidad interpretativa de los actores contribuía a la decadencia general del teatro español de principios de siglo. A su falta de preparación y al divismo de las primeras figuras y su ansia de lucimiento en detrimento de una correcta actuación de conjunto, se unían las exigencias de los empresarios y el exceso de estrenos, que impedía a los actores un estudio en profundidad de los personajes.

En los años veinte, varios directores (a la vez que autores), preocupados por esta situación participaron activamente en diversos intentos encaminados a la renovación escénica, creando teatros experimentales donde se ensayaban modelos globales alternativos a los del teatro comercial. Entre los primeros ensayos madrileños se sitúa la iniciativa de Cipriano de Rivas Cherif, uno de los hombres clave en la tarea renovadora de esos años, que dirige entre 1920 y 1921 el 'Teatro de la Escuela Nueva' con la intención de ofrecer un teatro de calidad interpretado por actores no viciados por su entrenamiento en el Conservatorio o en su paso por las compañías comerciales. Rivas Cherif comulgaba con los postulados de Gordon Craig, que preconizaba una transformación radical del espacio escénico. En este nuevo escenario, el intérprete debía interiorizar la intención del autor, armonizarse con el resto de los elementos del espectáculo, y evitar las actuaciones inducidas por sus emociones. Ya en 1920, Rivas Cherif aludía a la necesidad de renovar la base actoral como uno de los aspectos esenciales de la reforma, señalando: «Esta representación ha revelado hasta qué punto es fácil la regeneración de nuestra escena a base de actores y espectadores no contaminados por el ambiente $»^{2}$, para indicar más adelante la necesidad de «fundar cooperativas de cómicos y autores en sustitución de las empresas explotadoras del 'negocio' teatral, reeducar al cómico y al espectador libertándolos de los hábitos adquiridos en una rutina ayuna de ideal» ${ }^{3}$.

\footnotetext{
${ }^{1}$ ANGULO EGEA, María. «De Moratín a Valle Inclán. Más de cien años de batalla teatral». Cuadernos dieciochistas, 2004, 5, pp. 189-202; la cita en la p. 199.

${ }^{2}$ Se refería a la representación de la obra de Ibsen Un enemigo del pueblo, por el 'Teatro de la Escuela Nueva' en Madrid (junio de 1920).

${ }^{3}$ RIVAS CHERIF, Cipriano de. «Divagación a la luz de las candilejas». La Pluma, agosto de 1920, n. ${ }^{\circ}$ 3, pp. 113-119; la cita en la p. 119.
} 
También Valle-Inclán tenía una opinión negativa sobre los actores de su tiempo: «Los cómicos españoles son todos muy medianos [...]. Y no hablemos de las compañías, de los 'conjuntos'... Son peores aún» (Heraldo de Madrid, 14-VIII-1926); más adelante declararía: «Los cómicos de España no saben todavía hablar. Balbucean. Y mientras no haya alguno que sepa hablar, me parece una tontería escribir para ellos. Es ponerse a nivel de los analfabetos» ( $A B C, 23-\mathrm{VI}-1927)$. En efecto, Valle percibe que la preparación de los actores de la época para enfrentarse al modelo de actor y al tipo de declamación que imponía la preceptiva moderna era muy deficiente estando, como estaban, más habituados a la sobreactuación propiciada por el drama rural o romántico que a la riqueza en matices expresivos y declamatorios que el nuevo teatro exigía.

Numerosos investigadores se han ocupado de los distintos aspectos que configuraron los teatros experimentales surgidos en la España de los años veinte, como los decorativos, escenográficos, de dirección, etc., pero la labor interpretativa de los actores apenas se ha examinado. Lo cierto es que un buen número de estos actores eran además, autores que se sentían atraídos por el teatro considerado como un todo integral, y gustaban también de participar en la dirección e incluso intervenir en la escenografía. Nadie como ellos para tratar de mostrar el modo en que los actores debían de interpretar sus propios textos. Como señalaba M. Fernández Almagro ( $\mathrm{La} \mathrm{Voz}$, 7I-1929) al referirse a la triple empresa de autor, actor y director acometida por Rivas Cherif en Un sueño de la razón: «Mayor lealtad de un autor para su obra no cabe». También se ha indicado (J. Castellón en Informaciones, 1-II-1930) que la experiencia actoral le permitía al autor ajustar mejor sus nuevas obras dramáticas a las lógicas limitaciones de los recursos interpretativos: «A todos los autores conviene, pues tal enseñanza: la que se adquiere interpretando las propias obras».

Es cierto que otras razones, algunas tan prosaicas como la exigüidad de los locales y la elevada cotización de los actores profesionales, favorecía que los autores se interpretaran a sí mismos, sin desdeñar actuar en obras de otras autorías. Tampoco pueden excluirse como razones, el gusto por el juego, la pura diversión y un cierto afán de notoriedad. Sin embargo, como indica Araquistain, los participantes de un teatro experimental «requieren una buena dosis de espíritu de sacrificio en sus directores, autores y comediantes; el negocio rara vez es brillante, y la gloria popular, si llega, tampoco suele ser inmediata. Pero de esos teatros de minorías salen a la larga los directores, autores y comediantes que han de renovar los teatros de muchedumbres cuando el público se ha fatigado de la monotonía e insustancialidad de los valores tradicionales $»^{4}$. Aunque la educación del público se consideraba clave, el prestigioso crítico E. Díaz-Canedo (El

\footnotetext{
${ }^{4}$ ARAQUISTAIN, Luis. La batalla teatral. Madrid: CIAP, 1930, p. 73.
} 
Sol, 4-XII-1926) sostenía que la influencia directa de los actores de los teatros de arte sobre los gustos del espectador era nula ya que al incorporarse al teatro comercial estos mismos actores se veían obligados a readaptar sus planteamientos. Pero sin duda estos nuevos teatros formarían un público más exigente que, a su vez, reclamaría una mayor calidad interpretativa.

Por otra parte, la afición de determinados autores a interpretar es conocida ${ }^{5}$. En cuanto a la de Valle-Inclán no se puede obviar su concepción de la vida como teatro, donde él toma el papel del actor principal. Esta postura, cuidadosamente fomentada a lo largo de los años, ha sido señalada por muchos de sus contemporáneos. Pero además, Valle intervino de joven como actor en La comida de las fieras de Benavente interpretando la figura de un poeta modernista y en Los reyes en el destierro de Daudet, aunque en ambos casos sin mayor éxito ${ }^{6}$. Su actividad como conferenciante y recitador de sus obras fue extensa y muy valorada ${ }^{7}$. Ilustrativa de su aptitud puede ser la impresión que causó en su amigo Rivas Cherif la escucha de la lectura de su obra Romance de lobos; la intencionalidad con la que el autor marca un simple inciso en una de las acotaciones del texto conmueve a Rivas, llegando a hacerle afirmar: «A contadísimos actores, entre los más grandes, juzgo capaces de expresar, como don Ramón aquella tarde, el misterio trágico-grotesco del estrafalario personaje con tan pocas palabras descrito» ${ }^{8}$.

En las experiencias renovadoras más notables del los años veinte, el núcleo actoral se trasvasa de uno a otro ensayo y acaba por conformar un grupo que, a pesar de las consabidas bajas e incorporaciones, terminará constituyendo un auténtico elenco, cuya evolución puede seguirse a través de las críticas teatrales y otros documentos de la época. En este trabajo me ocuparé de la recepción crítica de las actuaciones, en especial la del grupo como tal y la de los autores que, como hombres de teatro integrales, intervinieron en las compañías 'El Mirlo Blanco' (1926-27), 'El Cántaro Roto' (1926) y 'Caracol' (1928-29).

\footnotetext{
${ }^{5}$ Además de los que intervinieron en estas experiencias teatrales, merece señalarse el gusto por actuar de otros dramaturgos coetáneos. Así por ejemplo, María Martínez Sierra en Gregorio y yo (Valencia: Pretextos, 2000, p. 98) menciona que «A Benavente, lo mismo que a Gregorio Martínez Sierra, atraíale fuertemente la afición a representar». Más adelante, indica que ambos participaron como actores en una función de aficionados donde se representó Cenizas de Valle-Inclán.

${ }^{6}$ GONZÁLEZ MARTEL, Juan Manuel. «La amistad de Alejandro Sawa y Ramón del Valle-Inclán en el archivo de los Sawa (1862-1984)». Madrygal, 2006, 9, pp. 73-84; la cita en la p. 77.

${ }^{7}$ SÁNCHEZ-COLOMER, María Fernanda. Valle-Inclán orador. Tesis doctoral: Universidad Autónoma de Barcelona, 2002, p. 75.

${ }^{8}$ RIVAS CHERIF, Cipriano de. «Más cosas de don Ramón». La Pluma, enero de 1923, n. ${ }^{\text {o }} 32$, pp. 90-96; la cita en la p. 91.
} 
Según Caro Baroja, 'El Mirlo Blanco' nace una tarde de otoño en la tertulia de la casa familiar de los Baroja a raíz de una improvisada representación de Don Juan Tenorio, en la que cada cual leyó su parte o la recitó si se la sabía de memoria9 ${ }^{9}$ Aquí se demuestra lo cierto de la afirmación de Pío Baroja, que aseguraba que «Valle-Inclán se sabía todo el Diablo Mundo, todo el Don Juan Tenorio, de memoria» ${ }^{10}$, ya que en casa de los Baroja causó sensación al recitar entero y sin vacilaciones el papel de Doña Brígida. Aunque Caro Baroja apunta que «Valle había intentado ser cómico pero su ceceo extraño le impidió seguir esa actividad», más probable parece que el mayor handicap en su frustrada carrera de actor fuera su mutilación a raíz del incidente del Café de la Montaña. Tanto en 'El Mirlo Blanco' como en las siguientes experiencias teatrales Valle-Inclán no participaría como actor.

Otros documentos escritos en tiempo más cercano a los hechos sitúan la jocosa representación del Tenorio al final del año, cuando ya la compañía había cosechado notables éxitos y relacionan esta ocurrencia con la necesidad de contrarrestar la obsequiosa benevolencia con la que los críticos trataron a los actores desde el comienzo de las representaciones ${ }^{11}$. La versión de Rivas Cherif parece dar más verosimilitud a esta segunda opción al relatar el desencadenante de los inicios de 'El Mirlo': «Ricardo [Baroja] nos leyó algún ensayo dramático de su minerva, y ello fue causa de que a mí se me ocurriera organizar un escenario de cámara en aquél mismo lugar que, con el nombre de 'Teatro del Mirlo blanco' [...], tuvo cierto renombre...». El propio Rivas indica la exclusividad del experimento: la entrada estaba limitada por lo exiguo del local y los autores, en su mayoría, se doblaban como «intérpretes de sí mismos» ${ }^{12}$.

Caro Baroja describe el comedor de la casa de los Baroja en la calle Mendizabal como un cuarto grande, rectangular, de techo alto, que al fondo quedaba dividido en dos partes; en la inferior había una chimenea y un diván bajo un arco, y en la superior quedaba el apartamento que su tío Ricardo Baroja llamaba «el chiscón». Éste tenía tres arcos que daban sobre el comedor, de forma que lo que quedaba debajo podía pasar como escenario $^{13}$. Al rememorar la trayectoria de 'El Mirlo', Carmen Baroja, alude a que los actores aceptaban las molestias ocasionadas por lo reduci-

${ }^{9}$ CARO BAROJA, Julio. Los Baroja. Madrid: Taurus, 1972, p. 185.

${ }^{10}$ BAROJA, Pío. Obras Completas. Madrid: Biblioteca Nueva, 1949, p. 430.

${ }^{11}$ AGUILERA SASTRE, Juan; AZNAR SOLER, Manuel. Cipriano de Rivas Cherif y el teatro español de su época (1891-1967). Madrid: Publicaciones de la Asociación de Directores de Escena de España, 1999, p. 110. Los testimonios proceden de Ricardo Baroja y Melchor Fernández Almagro.

${ }^{12}$ RIVAS CHERIF, Cipriano de. Retrato de un desconocido. Vida de Manuel Azaña. Barcelona: Grijalbo, 1980, pp. 145-146.

${ }^{13}$ CARO BAROJA, op. cit., pp. 183-184. 
do del espacio («en un rincón de un metro escaso hemos estado hasta seis personas, asfixiadas de calor, esperando el momento de salir a escena») con «simpática cordialidad». También recuerda que el escenario, además de pequeño, no tenía salidas ni puertas laterales, de manera que todos los actores tenían que entrar por la embocadura con la luz apagada para no perder el efecto de la caracterización ${ }^{14}$.

Por más que 'El Mirlo Blanco' fuera un verdadero teatro experimental, tuvo una gran repercusión en la prensa de la época. A ello contribuyó la labor de críticos teatrales, del propio Rivas, de su antigua colaboradora Magda Donato y de Enrique Díez-Canedo, uno de los asiduos a las representaciones. Todos ellos cuidan bien de diferenciar esta experiencia de las de los teatros de aficionados, ya que, como afirma Díez-Canedo, los aficionados no dejan de ser «personas muy simpáticas y respetables que gustan de poner privadamente en escena lo mismo que se aplaude en público a las compañías formales» (El Sol, 9-II-1926). Lo cierto es que el experimento tiene gran notoriedad y recibe el elogio de hombres de teatro tan prestigiosos como Adrià Gual y Eduardo Marquina. El propio Federico García Lorca, en carta a Fernández Almagro (fechada entre finales de febrero y principios de marzo de 1926) y en relación con una comedia suya «cuyos personajes son ampliaciones fotográficas», le pregunta: «¿La podremos presentar en el teatrillo nuevo de Cipriano?» ${ }^{15}$.

La creación en otoño de 1926 de un nuevo escenario en el Círculo de Bellas Artes, ofrecería a los componentes de 'El Mirlo Blanco' el poder salir de su reducido ambiente y contar con una sede estable. Valle-Inclán, que ejercía en 'El Mirlo' una cuidadosa supervisión de la interpretación de los actores pasó a ser director de un nuevo ensayo de teatro, 'El Cántaro Roto', pero su enfrentamiento con la directiva del Círculo impidió que el nuevo intento superase los dos espectáculos teatrales; el primero, los días 19 y 20 de diciembre y el segundo, ocho días después ${ }^{16}$.

${ }^{14}$ BAROJA NESSI, Carmen. «Desde el nido de 'El Mirlo blanco'». La Gaceta Literaria, abril de 1927, n. $^{\circ} 8$, p. 5. Las condiciones del escenario no fueron mucho mejores en las siguientes experiencias. Así, Valle-Inclán llegaría a declarar: «El teatrito del Círculo de Bellas Artes es una birria. El escenario mide desde la decoración del foro al telón de boca un metro y treinta centímetros. En esta miniatura de escenario [...] los actores no se pueden mover...». (Heraldo de Madrid, 1-I-1927). Igualmente, el escenario de la Sala Rex carecía de «embocadura, de telón, de decoraciones. Sobre la tarima, breve y reducida, actúan los actores». (E. Estevez Ortega, Nuevo Mundo, 7-XII-1928). Sin embargo, Rivas (ABC, 4-X1928), se muestra satisfecho con las condiciones de la sala y recuerda que él solicitaba «Un local reducido [...]. Nada más que una sala y un tabladillo».

${ }^{15}$ Parcialmente reproducida en GIL FONBELLIDA, María del Carmen. «Federico García Lorca y Cipriano Rivas Cherif: Una experiencia renovadora en el teatro profesional (19201935)». Dicenda, 1999, 17, pp. 63-88; la cita en la p. 66.

${ }^{16}$ En la primera función de 'El Cántaro' se representó La comedia nueva o El café (L.F. Moratín) y Ligazón (R. Valle-Inclán); en la segunda se repuso la obra de Moratín junto con Arlequín, mancebo de botica (P. Baroja). 
Tras el paréntesis que constituyó la experiencia de 'El Cántaro Roto', todavía 'El Mirlo Blanco' ofrecería dos nuevas representaciones, la primera (quinta en el cómputo total) en su sede habitual, y la segunda en Irún (el 27 de agosto de 1927) y a beneficio del Hospital de esa ciudad ${ }^{17}$. Poco tiempo después la resentida salud de Rivas Cherif, alma del grupo, determina el cese de toda actividad. Por tanto, con esta salida se dio por finalizada esa interesante tentativa.

Al año siguiente, Rivas Cherif alentado por el apoyo de un industrial que le ofrece en alquiler un sótano en la calle Mayor en condiciones ventajosas (al que se le llamaría Sala Rex), forma la compañía 'Caracol' con la pretensión de reanudar la lucha por la renovación del teatro. Después de asumir su dirección, indica: «Quise contar al punto con la colaboración de mis amigos escritores y artistas. [...] Desde luego obtuve además la cooperación de Magda Donato, Esther Azcárate, Natividad Zaro, Carmen de Juan, Regina, Josefina Hernández, Salvador Bartolozzi, Eusebio de Gorbea [...] para constituir un grupo teatral renovador de otros ensayos de grata y reciente memoria...» (Heraldo de Madrid, 5-XI-1928).

La apertura de la Sala Rex el 24 de noviembre de 1928 fue ampliamente reseñada en la prensa, que siempre mostró su apoyo a estos ensayos de innovación teatral ${ }^{18}$. No obstante, algunos críticos, como L. Calvo aluden a «un público híbrido: algunos snobs, algunos curiosos de eso que llaman vanguardia, algunos humoristas y murmuradores [...]. Un público blando, como el del Lyceum femenino» (ABC, 25-XI-1928). En todo caso, la duración de este tercer experimento fue breve: a primeros de enero de 1929 la sala se cierra por problemas con la censura.

\section{LA VALORACIÓN DEL ELENCO}

Ya desde el comienzo de las representaciones de 'El Mirlo Blanco', la crítica destaca la actuación del conjunto de actores que serán calificados más adelante como «profesionales de la afición» (Heraldo de Madrid, 28III-1927). Por ejemplo, Andrenio ( $L a$ Voz, 14-V-1926) indica que lo más notable de las funciones reside en la seguridad y acierto del conjunto de intérpretes «sin antecedentes profesionales conocidos», de forma que 'El Mirlo Blanco' "podría presentar en competencia con las compañías de veras su batallón de Talía, y a algunas les llevaría ventaja». Díez-Canedo, que ya estima desde el comienzo el acierto del conjunto por la «sobriedad in-

${ }^{17}$ El programa de quinta función de 'El Mirlo' estuvo formado por El maleficio y El Torneo (R. Baroja), y El café chino (E. Villaseñor); el de la última por El gato de la Mère Michel (C. Baroja), El Torneo (R. Baroja), y El café chino (E. Villaseñor).

${ }^{18}$ En la primera función de 'Caracol' se representó Lo invisible (Azorín) y Un duelo (A. Chejov). 
teligente» que consigue dar a sus interpretaciones (El Sol, 23-IV-1926), afirmará más tarde (La Nación, 16-V-1926) que los actores de 'El Mirlo', «capaces de entender un texto e interpretarlo fielmente», «merecen ver consignados sus nombres en el frontón del templo de Talía». Igualmente, los alaba G. Olmedilla (Heraldo de Madrid, 11-V-1926), que destaca su cuidadosa labor de intérpretes «que lo son admirables».

Según opina Andrenio ( $L a$ Voz, 25-XII-1926), la razón de que ya en la primera función de 'El Cántaro Roto' se pudiera ver un cuadro artístico bien conjuntado reside en que su base es el núcleo central del grupo de 'El Mirlo', con el que comparte también su propósito, aunque se haya renovado alguno de sus elementos. El profesor Lavaud atribuye el éxito de 'El Cántaro', entre otras virtudes, a la cohesión de los intérpretes que formaron un grupo homogéneo y estable, sin apenas diferencia con el de 'El Mirlo' ${ }^{19}$.

Las apreciaciones del conjunto siguen teniendo el mismo tono laudatorio durante las representaciones de 'Caracol'. Como ejemplo, se recogen varias opiniones sobre la interpretación de Orfeo: Rosa Chacel estima que «Difícilmente se conseguirá una representación menos empañada por el actor, más íntegramente respetada ${ }^{20}$, mientras que E. Díez-Canedo en $E l$ Sol (20-XII-1928), destaca que los actores «sirvieron fielmente al texto, con esa lealtad que da valor a las fotografías de 'amateur' y no se halla nunca en las pruebas retocadas del mejor fotógrafo». Por último, M. Fernández Almagro ( $\mathrm{La}$ Voz, 20-XII-1928), indica: «Contribuyó al éxito la atinada interpretación. Magda Donato, Cipriano Rivas, Gloria Martínez Sierra, Gorbea, Lluch, colmaron con el acierto el reparto de la tragedia de Cocteau».

Las escasas críticas negativas al elenco que se han podido encontrar (si bien no secundadas por todos los críticos) se refieren a la cuarta velada de 'Caracol' (29-XII-1928) ${ }^{21}$. De ella, el crítico anónimo de Estampa (1-I1929) aprecia el conjunto de la representación, aunque apostilla que mejoraría si los actores «se decidieran aprender de memoria sus papeles». La valoración de L. Calvo $(A B C, 30-X I I-1928)$ es más radical, indicando «que los actores del 'Caracol' se esforzaron en desvirtuar [la representación de Asclepigenia] con una interpretación a todas luces lamentable [...]. Sobre que la Asclepigenia no debió ser representada [...] los actores del 'Caracol' parecían empeñados en destruir sus encantos».

${ }^{19}$ LAVAUD, Jean-Marie. «El nuevo edificio del Círculo de Bellas Artes y 'El Cántaro roto', de Valle-Inclán». Segismundo, 1975, 21-22, pp. 237-254; la cita en la p. 246.

${ }^{20}$ CHACEL, Rosa. «Cocteau-Orfeo». Revista de Occidente, 1928, LXVI, pp. 389-392; la cita en la p. 392.

${ }^{21}$ En el cuarto programa de 'El Caracol' se representó Asclepigenia (J. Valera); Duo (P. Masip) y Si creerás tú que es por mi gusto (J. Benavente). 
Por último, requiere una mención especial la interpretación de conjunto en dos obras. En la primera, Ligazón, 'Auto para siluetas' (de ValleInclán), representada en la tercera serie de 'El Mirlo Blanco', la puesta en escena de Rivas Cherif dota a los personajes de las dos dimensiones de las siluetas. A costa de sacrificar su lucimiento, los actores consiguen dar a ese mundo bidimensional una vitalidad intensa e imborrable, «que otros miles de actores [...] no lograrían jamás. Y no, a fe, porque el texto sea irrepresentable [...] sino porque a la mayoría de esos miles de actores que no actúan en 'El Mirlo Blanco' les falta el principal motor entusiasta del actor: la disciplina, la servidumbre heroica de la obra tal y como expresamente escribió el autor que se la sirviera [...]. El actor [...], puesto que su misión es dar apariencia de vida a la ficción de un drama, tiene, contrariamente al héroe, su heroísmo en ser disciplinado y no hacer ni un parpadeo más de lo que su papel le ordena. En este sentido, los intérpretes de Ligazón llegan al heroísmo y merecen compartir con don Ramón el laurel del triunfo». La interpretación le parece por lo tanto, a G. Olmedilla (Heraldo de Madrid, 11-V-1926), inmejorable ${ }^{22}$. El reparto de Ligazón se repite en la primera función de 'El Cántaro', por eso no es de extrañar que la crítica subraye la autoridad con la que intervinieron los actores en esta representación.

La segunda, es la interpretación de Un sueño de la razón de Rivas Cherif que trata, audazmente para la época, un caso de lesbianismo y se estrena en el quinto espectáculo del 'Caracol'. En Heraldo de Madrid (7I-1929), Paulino Masip, después de resaltar la valentía de la experiencia teatral, indica que los espectadores aplaudieron repetidamente al autor y a los intérpretes: el propio Rivas, Natividad Zaro y Gloria Martínez Sierra. De ambas actrices resalta su abnegada y difícil labor en papeles de creación poética para los que no tenían ayuda, ni en la realidad cotidiana de la vida, ni en los que en otras obras hubieran podido representar. Por su parte, M. Fernández Almagro ( $L a$ Voz, 7-I-1929), en una crítica salpicada de consideraciones de índole moral y después de indicar que algunas personas, «yo no sé hasta qué punto autorizadas», pusieron reparos a la interpretación, señala: «no seré yo por esta vez, quien reproche a la señora Zaro y a la señorita Martínez Sierra — bellas e inteligentes siempre- y al Sr. Rivas su falta de documentación en la realidad». En todo caso, esta obra causará el suficiente escándalo y polémica como para que la censura centre su atención en las actividades de la Sala Rex.

${ }^{22}$ Los intérpretes de Ligazón fueron: Carmen J. de Benito, Josefina Blanco, Isabel de Palencia, F. García Bilbao y el propio Rivas Cherif. 


\section{LOS BAROJA, ACTORES}

La participación de los hermanos Baroja se ciñe a la experiencia de 'El Mirlo': ambos actúan desde el primer espectáculo pero, a diferencia de su hermano, don Pío pronto se quedará al margen ${ }^{23}$. De su actuación, Díez-Canedo (El Sol, 9-II-1926) destaca «la naturalidad con que don Pío Baroja, en un rincón de la escena leía el periódico, y decía, sin tropezar, las escasas frases de su papel!». El crítico de Heraldo de Madrid (R. M., 8-II-1926) celebra que, en su papel de lector de periódico en Adiós a la bohemia, Pío Baroja haya elegido precisamente su diario: «muchas gracias don Pío»; de su intervención verbal destaca irónicamente que «Se sabe el papel y lo dice con la intención misma que pondría el autor».

Mejores críticas obtiene en su papel como licenciado Pantalón en Arlequín... «un papel hecho a su medida», según comenta Ortega ${ }^{24}$; su interpretación da un «relieve extraordinario del señor Pantalón» (R. M., Heraldo de Madrid, 27-III-1926). También el crítico de ABC (25-III-1926) señala la actuación de Pío Baroja «representando el personaje principal en forma de boticario, pero de boticario del viejo y gran estilo. Quien no ha visto a Pío Baroja representar el papel de boticario, y con qué maestría, ignora el gran placer de la risa de la mejor procedencia literaria». Andrenio ( La Voz, 14-V-1926), confiesa su sorpresa al ver en Arlequín... «al propio Pío Baroja convertido en un excelente actor, en un barba que haría buen papel en cualquier escenario. No lo esperaba de este gran escritor [...] que tiene fama de reconcentrado y huraño...». Por último, E. DíezCanedo en La Nación (16-V-1926) comenta: «Pío Baroja, que ya había salido a la escena como actor, en un papel de pocas palabras en el Adiós..., fue un perfecto señor Pantalón. A la gravedad del personaje sustituía en su cara una constante sonrisa» ${ }^{25}$.

Esta insólita actitud risueña de don Pío contrasta con su carácter retraído; el propio Rivas Cherif indica: «Pío, de suyo huraño e importante, desdeñaba por lo general nuestra compañía ${ }^{26}$. Su afán participativo en las primeras representaciones de 'El Mirlo' parece indicar la condición de juego con la que debió haberse tomado su intervención en estos ensayos. En

${ }^{23}$ En el primer espectáculo de 'El Mirlo' se representó el prólogo y epílogo de Los cuernos de don Friolera (R. Valle Inclán); Marineros vascos (R. Baroja) y Adiós a la bohemia (P. Baroja) y en el segundo, Miserias comunes (O'Henry), Diálogo con el dolor (I. de Palencia), Trance (C. de Rivas) y Arlequín, mancebo de botica (P. Baroja). Esta última obra también se representaría en el tercer espectáculo.

${ }^{24}$ BAROJA NESSI, 1927, op. cit.

${ }^{25}$ Isabel de Palencia, a su vez, autora y actriz en 'El Mirlo Blanco', recuerda en sus memorias que Pío Baroja no podía contener la risa nerviosa. PALENCIA, Isabel de. I Must have Liberty. Nueva York: Longmans Green \& Co., 1940, p. 189.

${ }^{26}$ RIVAS CHERIF, 1980, op. cit., p. 145. 
efecto, Carmen Baroja, al relatar en sus memorias la dificultad que supuso encontrar quien diera la réplica a la primera actriz Nati González en Adiós..., refiere que Pío se prestó «gustosísimo» a representar tal papel, pero su actuación fue descartada al darle al personaje en los ensayos un aire demasiado monótono ${ }^{27}$.

Aunque son relativamente escasas las reflexiones de Pío Baroja sobre el teatro, la mayoría de sus juicios son negativos: «... no me produce éste [el teatro] gran entusiasmo, y hasta tengo cierta antipatía por él» ${ }^{28}$. Su desdén se basa en razones que van desde la aversión por las actividades colectivas hasta su concepción del teatro como «molde pequeño y arcaico para la vida moderna», que desde hace tiempo «ha dejado de inventar para repetirse $»^{29}$. Sin embargo, Pío Baroja, entusiasmado con la actuación de Nati González en Adiós..., escribió en una mañana Arlequín... para que fuera representado en la segunda serie de funciones de 'El Mirlo'. Su texto responde a su teoría de que sólo es posible crear teatro sobre personajes 'teatrales'. Probablemente (como subraya Rey Faraldos ${ }^{30}$ ), la experiencia de 'El Mirlo' fue para él la única oportunidad de acercarse al teatro en su aspecto lúdico y desenfadado, lejos de condicionamientos de público y empresarios.

Caro Baroja no tiene demasiado buena impresión del trabajo interpretativo en la primera representación de Marineros vascos, que Ricardo Baroja había adaptado partiendo de un cuento de don Pío: «No resultó demasiado bien porque ninguno de los actores tenía capacidad de imitar el aire ni la manera de hablar de un campesino vasco» ${ }^{31}$. El crítico de Heraldo de Madrid (R. M., 8-II-1926) se limita a destacar la plasticidad que Ricardo confiere al personaje: «un marinero vasco capaz de seducir la apetencia pictórica de Zubiaurre». J. García Olmedilla también en Heraldo de Madrid (11-V-1926) al hacer la crónica de la segunda representación de la obra, menciona la «sobriedad verdaderamente dramática» con que Ricardo Baroja la protagoniza, y Andrenio ( $L a$ Voz, 14-V-1926) destaca el «mucho carácter que le daba Ricardo Baroja al principal personaje» de Marineros vascos. Por último, y en relación con la quinta serie de las representaciones de 'El Mirlo', R. M. le dedica en Heraldo de Madrid (2-IV-1927) un triple aplauso: como autor, escenógrafo y actor «éuskaro euskarizante (vascoandaluz en el fondo)». También es mencionada su ac-

${ }^{27}$ BAROJA NESSI, Carmen. Recuerdos de una mujer de la generación del 98. Barcelona: Tusquets, 1998, p. 86.

${ }^{28}$ BAROJA, Pío, op. cit., p. 783.

${ }^{29}$ Las dos últimas citas de P. Baroja están recogidas en REY FARALDOS, Gloria. «Pío Baroja y 'El Mirlo blanco'». Revista de Literatura, 1985, XLVII, 93, pp. 117-127.

${ }^{30}$ Ibidem, p. 127.

${ }^{31}$ CARO BAROJA, op. cit., p. 186. 
tuación en Adiós..., donde: «incorpora a un camarero ideal, magnífico en su realidad» (R. M., Heraldo de Madrid, 8-II-1926), aunque, como informa Carmen Baroja, había sido descartado como primer actor porque componía un personaje «despreocupado, poco romántico» ${ }^{32}$. En definitiva, las intervenciones de Ricardo Baroja como intérprete (por otro lado, bastante numerosas) no despertaron significativos elogios en los críticos. Más bien se aceptó su participación como un hecho inevitable al celebrarse los espectáculos en su casa; su actividad como autor y, sobre todo, como decorador fue por el contrario muy bien valorada.

\section{LA COHERENCIA DE RIVAS CHERIF}

La afición de Cipriano de Rivas Cherif por el teatro comienza en su niñez y no decaerá hasta su muerte, por más que familia y amigos trataron de desalentarle, dado lo insustancial del teatro español de la época ${ }^{33}$. Según él mismo relata en Retrato de un desconocido, a principios de 1925 emprende una gira teatral con la compañía de Mimí Aguglia, en la que, además de asesorar y participar en los montajes, desempeña pequeños papeles en dos obras de Pirandello ${ }^{34}$ (Cada cual a su manera y Seis personajes en busca de un autor). De la correspondencia entre Rivas Cherif y Azaña se tienen noticias de esta actividad; Azaña, en una carta fechada en Madrid (25-IV-1925), tras comunicarle a Rivas el envío de su obra La Costumbre, le pregunta «¿Es que van a estrenarte esta obra? ¿Vas a representarla tú mismo? Martínez Sierra nunca ha salido a las tablas; pero sí Don Jacinto, Valle, y... Sacha Guitry. Sin hablar de Poquelin, autorizado ejemplo...» ${ }^{35}$. Un mes más tarde, en carta a Azaña ([Barcelona] 25-V-1925), Rivas le cuenta el fracaso de su intervención en Cada cual a su manera: «La cosa es que salí con mi fraquecito a decir un prologuito que nos había hecho mucha gracia a Ferrau, a Alfredo y a mí mismo, claro, y que no había dicho veinte palabras [...] cuando los espectadores de un proscenio ya me decían a su vez «Prou, prou» [...] Transcurrió luego la representación sin tiros [...] a la gente le gustó poco, y hemos tenido, salvo yo, que fui el que estuvo mal, muy mala prensa» ${ }^{36}$. El día 2 de agosto desde San Sebastián, le comunica «El martes se estrena Seis personajes y yo tengo

${ }^{32}$ BAROJA NESSI, 1998, op. cit., p. 65.

${ }^{33}$ Él mismo confesaba en su «Autobiografía» (incluida en Aguilar y Aznar, op. cit., pp. 465-467) su pasión por el teatro y concretamente por actuar: «Quise ya entonces [1909] dedicarme al teatro como actor».

34 ANDERSON, Andrew A. «Coincidencias y paralelismos: las carreras teatrales de Ricardo Baeza y Cipriano Rivas Cherif». Actas del XII Congreso de la Asociación Internacional de Hispanistas. Birmingham, 1995, pp. 41-49; la cita en la p. 44.

35 RIVAS CHERIF, 1980, op. cit., p. 615.

36 Ibidem, pp. 619-620. 
que decir breves y sentidas palabras al principio» ${ }^{37}$. Incluso en 1928 , entre su participación en 'El Mirlo' y 'Cántaro', Rivas representó en el teatro comercial dos papeles episódicos, uno escrito para él en la comedia iNo quiero, no quiero! de J. Benavente, y otro en La comida de las fieras, del mismo autor ${ }^{38}$.

Su afición y éxito como recitador de poesía y lector de textos teatrales era ya reconocida antes de la fundación de 'El Mirlo'. Aunque en estos teatros renovadores participó también como recitador, el análisis de esta faceta queda fuera de los límites de este trabajo.

La labor de Rivas Cherif como actor en estos teatros experimentales comienza con la primera representación de 'El Mirlo' y continúa hasta las últimas del 'Caracol', participando en numerosas obras ${ }^{39}$. La crítica se mostró siempre elogiosa; en este trabajo sólo se destacarán algunas de las referencias expresas a sus actuaciones individuales. Es pertinente recordar aquí los términos en que le describe Carmen Baroja, «pequeño de estatura, más bien rubio, bien proporcionado con la cara correcta, y parlanchín, cuentero, gracioso y divertido como nadie. Conocía a todo el mundo, se reía de todo y alegraba con su conversación la reunión donde estuviera». Y más tarde: «Comenzaron los ensayos, en donde Rivas era el alma de todo. Él citaba a la gente, repartía los papeles, imitaba a Valle-Inclán, recitaba como nadie...» ${ }^{40}$.

Aunque al crítico de Heraldo de Madrid (R. M., 8-II-1926) le parece discutible su participación en el Prólogo de Los cuernos de don Friolera al decir su papel «de un modo 'sui generis' que sería perfecto si no fuese por ese frecuente adelantamiento del mentón y de los labios, que no parece sino que el recitador va cazando al aire las palabras», como voz de los muñecos valora positivamente su actuación que «es sencillamente deliciosa en sus cambiantes tonos y matices. ¡Muy bien, Cipriano!». El mismo crítico aplaude la actuación de Rivas en Adios... donde interpreta un «chulo castizo. Cuatro frases. Dos ademanes, unos pasos y un gran éxito». Lo versátil en la caracterización de sus personajes es resaltado también por M. Fernández Almagro ( $\mathrm{La} \mathrm{Voz,} \mathrm{28-III-1927)} \mathrm{que,} \mathrm{después} \mathrm{de} \mathrm{alabar} \mathrm{la} \mathrm{labor}$ interpretativa de su pareja en El maleficio, indica que Rivas lo complementa, «jugando certeramente el tornasol de su papel».

La interpretación que hace Rivas de Arlequín, un personaje, que, según informa Carmen Baroja, fue creado para él por don Pío, fue acogida con relevantes críticas. Así, R. M. (Heraldo de Madrid, 27-III-26) destaca la actuación de Rivas que «magníficamente caracterizado y vestido por

\footnotetext{
37 Ibidem, p. 631.

38 «Autobiografía» de Rivas Cherif, incluida en Aguilera y Aznar, op. cit., p. 471.

${ }^{39}$ Para apreciar la labor renovadora y multidisciplinar de Rivas Cherif durante los años 1926-29, véase Aguilera y Aznar, op. cit., pp. 109-133.

40 BAROJA NESSI, 1998, op. cit. pp. 83-84.
} 
Mignoni, pirueteó de lo lindo. [...] La interpretación cherifiana fue fidelísima y muy inteligente». Díez-Canedo en La Nación (16-V-1926) también subraya el trabajo del intérprete «en quien el atolondrado mancebo encontró toda su travesura como un actor consumado». También Andrenio ( $L a$ Voz, 14-V-1926), subraya la excelente actuación de Rivas («apasionado del teatro, crítico competente, gran promotor de todos los teatros de arte habidos y por haber»).

Ya en relación con las funciones del 'Caracol', Juan G. Olmedilla en Heraldo de Madrid (20-XII-1928) alaba de Rivas, tanto su labor de dirección en Orfeo como su interpretación del protagonista al que supo dar «el debido relieve, ya cómico ya trágico». Igualmente, Arturo Mori en El Liberal (20-XII-1928) destaca, calificándola como muy notable, la doble labor de Rivas en la obra de Cocteau.

\section{LA BREVE PARTICIPACIÓN DE AZORÍN}

En la primera función de 'Caracol' se representó una obra de Azorín, Lo Invisible (el Prólogo y dos de sus piezas en un acto: La arañita en el espejo y Doctor Death, de 3 a 5) en la que él mismo intervino como actor. Luis Calvo ( $A B C, 25-\mathrm{XI}-1928)$, se excusa de juzgar su actuación «tan breve y gris por la índole misma de su papel». Según Díez-Canedo ( $E l$ Sol, 25-XI-1928), Azorín dio al público la impresión que pretendía: «la de un autor entre sus comediantes, un poco sorprendido por la insospechada importancia que adquiría uno de ellos». Sin embargo, Arturo Mori (El Liberal, 25-XI-28) al referirse a la actuación de Azorín («sin maquillarse, tal como es y con su voz y sus maneras») la juzga como una rotunda equivocación («el actor nos pareció muy mal»). Entiende que nunca será buen actor y no le hace falta «como no signifique para él un deseo irresistible». Y más negativa es aún la valoración de E. Estévez-Ortega (Nuevo Mundo, 7-XII-1928): «En la breve intervención que tuvo en el prólogo pirandeliano de su trilogía Lo invisible [...] nos dio cabal idea de sus aptitudes. Es decir de su falta de aptitudes [...]. Soso, quieto, sin saber accionar, parecía cohibido».

\section{Un OlvidAdo: Eusebio DE GORBEA}

Si bien no intervino como actor en obras de su autoría, merece ser reconstruida la participación en estos ensayos de renovación teatral de Eusebio de Gorbea (Madrid, 1881-Buenos Aires, 1948), militar de profesión, cuya ardiente vocación le había llevado desde muy joven al campo de las letras. El crítico Floridor ( $A B C, 21-X I I-1926)$ incluye el nombre de ¿Calibau? (sic) en la lista de intérpretes que actuaron en la primera fun- 
ción de 'El Cántaro'. En la biografía de su esposa, se indica que para evitar dificultades con el ejército, Gorbea había adoptado el pseudónimo de Juan Calibán ${ }^{41}$. También José L. Maynar en La Voz (20-XII-1926) incluye en la nómina de actores a Juan Caliban, indicando que es el «seudónimo tras el que se oculta otro distinguido novelista, unánimemente alabado» y del que destaca, junto a Rivas Cherif, sus aciertos «en la caracterización y la dicción».

$\mathrm{Su}$ nombre aparece por primera vez en la nómina de los actores de 'El Mirlo Blanco' en su quinto espectáculo. Su incorporación a la compañía se destaca de la siguiente manera: «Para esta última representación ha hecho la Empresa una importantísima adquisición con D. Eusebio Gorbea» ${ }^{42}$. En sus memorias, y después de referirse a la esposa de Gorbea, Carmen Baroja nos da testimonio de su persona: «El marido, militar, también simpático, [que] escribió alguna comedia con éxito, tenía una enorme afición por el teatro ${ }^{43}$. Igualmente, Margarita Ucelay, al referirse a Eusebio, señala que «Era además un excelente actor [...]. Hombre conocido y estimado en Madrid» ${ }^{44}$. En esta primera actuación en 'El Mirlo' llama la atención de la crítica; por ejemplo, R.M. (Heraldo de Madrid, 2-IV-1927) después de elogiar la labor de los intérpretes en su conjunto, señala que la actuación de Eusebio de Gorbea merece mención aparte, definiéndole como un «maestro sabio y eficaz».

Ya en 'Caracol', su actuación en la obra de Chejov, Un duelo, fue muy bien valorada por toda la crítica: según la opinión de Arturo Mori ( $E l$ Liberal, 25-XI-28) Gorbea se revela casi como un actor profesional. También G. Olmedilla (Heraldo de Madrid, 26-XI-1928) indica que la representación de Un duelo permitió admirar nuevamente el arte interpretativo de varios actores no profesionales, sobre todo el de Eusebio de Gorbea que: «se nos reveló en el rudo protagonista como todo un señor actor, dueño de los más conseguidos secretos de su arte. Justamente fue ovacionado». M. Albar en El Socialista (25-XI-1928) y L. Calvo en ABC (25-XI-1928) destacan, a su vez, la excelente interpretación de Magda Donato y de Gorbea en la comedia de Chejov.

${ }^{41}$ DORAO, Marisol. Los mil sueños de Elena Fortún. Cádiz: Universidad de Cádiz, 1999, p. 106. La esposa de Gorbea, Encarnación Aragoneses, es más conocida por su pseudónimo, Elena Fortún (tomado de la novela histórica Los mil años de Elena Fortún. Magerit, de Eusebio de Gorbea, publicada por Calleja en 1922), con el que firmaría la serie de cuentos infantiles más célebre de la literatura española.

${ }^{42}$ BAROJA NESSI, 1927, op. cit.

${ }^{43}$ BAROJA NESSI, 1998, op. cit. p. 107. Gorbea había estrenado en 1909 la comedia La muñeca de los viejos, premiada el año anterior por el diario El Liberal en la misma convocatoria en la que Rivas Cherif obtuvo el tercer premio.

${ }^{44}$ UCELAY, Margarita. «Introducción» a la edición crítica de Don Perlimplín con Belisa en el jardín de Federico García Lorca. Madrid: Cátedra, 1990, p. 147. 
También Díez-Canedo (El Sol, 25-XI-1928) señala que en la primera función de la Sala Rex, fue Eusebio de Gorbea quien se había revelado como un verdadero actor y después de recordar su reciente estreno como autor del drama rural Los que no perdonan ${ }^{45}$, concluye: «Gorbea conoce muy bien los secretos del oficio: tiene voz, gesto, ademán. Se le aplaudió con calor por todos».

El crítico de El Liberal (I. A., 30-XII-1928), al referirse a la interpretación de Asclepigenia, destaca con contundencia la actuación de Gorbea «el actor más cuajado que ha aparecido hasta la fecha en la Sala Rex» y asimismo aplaude el acierto con que fue capaz de resaltar (junto con Magda Donato) «todas las bellezas y todas las alusiones» contenidas en el diálogo Si creerás tú que es por mi gusto (de J. Benavente). Otro gran éxito lo consigue en su participación en Orfeo de Cocteau; Arturo Mori en El Liberal (20-XII-1928) lo señala como «un actor de tono». Luis Calvo $(A B C, 25-X I I-1928)$ destaca que al éxito de la obra de Cocteau contribuyeron sus intérpretes y en particular Rivas Cherif, Magda Donato y Eusebio de Gorbea.

En el mes de enero de 1929, comienzan los ensayos de la 'aleluya erótica' Amor de don Perlimplín con Belisa en su jardín de F. García Lorca que tenía previsto su estreno el 6 de febrero de 1929 junto con la obra de Suárez de Deza Por qué don Fabián cambia constantemente de cocinera ${ }^{46}$. Al morir ese mismo día la madre de Alfonso XIII se cierran los teatros por decreto oficial y aunque la obra no se estrena, continúan los ensayos. José Jiménez Rosado recordaba muy bien el gran efecto que hacía la cama colocada en el centro del escenario del que ocupaba su mayor parte, y donde los personajes protagonistas (el de don Perlimplín, provisto de unos enor-

\footnotetext{
${ }^{45}$ Drama en cuatro actos por el que recibió el premio Fastenrath de la Academia de la Lengua. Fue estrenado en el teatro Eslava (29-IX-1928) con cierto éxito: se hicieron 70 representaciones y se repuso la temporada siguiente en La Latina (VILCHES, María Francisca; DOUGHERTY, Dru. La escena madrileña entre 1926 y 1931. Madrid: Fundamentos, 1997, p. 486). Más adelante (1930), estrenaría Los amos de Curtidores en La Latina; Gerardo Ribas en Heraldo de Madrid (26-IV-1930), después de afirmar que Gorbea era «un dramaturgo de consistencia inusitada», califica la obra de sainete melodramático. Interesa señalar que, según se informaba en $\operatorname{La} V o z$ («Información teatral», 13-XI-1928), Eusebio de Gorbea era uno de los dramaturgos cuya obra se proponía representar la compañía 'Caracol'.

${ }^{46}$ Suárez de Deza también actuó en el grupo 'Caracol'. Igualmente, Felipe Lluch, uno de los actores habituales del conjunto desde los inicios de 'El Mirlo Blanco' tenía intención de ser autor (Aguilera y Aznar, op. cit., pp. 130 y 120). Si bien se refería a los actores profesionales, no deja de ser interesante señalar la opinión de Rivas Cherif sobre el 'actor como autor' (la circunstancia contraria de la aquí analizada): «son preferibles los [actores] que no leen más que los periódicos al día siguiente de un estreno, que los que tienen pretensiones de escritores. Algunas obras hay, pocas afortunadamente [...] de algún actor, de veinticinco o treinta años acá». (RIVAS CHERIF, Cipriano de. Cómo hacer teatro: Apuntes de orientación profesional en las artes y oficios del teatro español. Valencia: Pretextos, 1991, p. 180).
} 
mes cuernos, era interpretado por Eusebio de Gorbea) quedaban rígidamente presentados frente al público. Según Ángel del Río, crítico y amigo de García Lorca, el ministro de Gobernación, Martínez Anido, al enterarse de que un comandante del ejército muy conocido en Madrid iba a representar el papel de don Perlimplín, se había enfurecido y ordenado suspender la representación, amenazando con meter en la cárcel a autor, actor y director: «Esto es un ludibrio. Esto es un ultraje al ejército» ${ }^{47}$. La sala Rex quedó clausurada, la compañía 'Caracol' disuelta, el Amor... se prohibió por inmoral y su texto fue incautado.

Completamente olvidado a día de hoy, resulta interesante anotar aquí una breve referencia al encuentro de Eusebio de Gorbea con Rosa Chacel que tiene lugar años más tarde en la casa de Ricardo Baeza ${ }^{48}$, cuando todos ellos compartían el exilio en Buenos Aires. Como ya se mencionó, la autora había realizado una crítica sobre la representación de Orfeo, alabando la interpretación de sus actores. La figura de Gorbea, exiliado entre digno y excéntrico, despertó en Chacel un vivo interés, inspirándole el personaje de Damián Vallejo, uno de los mejor dibujados de su reconocida novela La sinrazón ${ }^{49}$. Damián era un fiel reflejo de Eusebio de Gorbea; los dos se encontraban fuera de su ambiente y sobre todo, de su tiempo. En la novela (pp. 150-159) se pueden rastrear numerosos rasgos biográficos que los identifican, incluyendo su final: ambos, el personaje y su supuesto inspirador, incapaces de superar la dureza del exilio y viviendo la condena de una terca inadaptación, acaban suicidándose.

Para cerrar esta nota, valga el comentario de su propia esposa, expresado en una carta escrita a una de sus mejores amigas, Inés Field (8-I1949), a los pocos días de la muerte de Eusebio, en la que reconoce la vocación teatral de su marido hasta en la escenificación de su suicidio: «Veo claro todo el proceso y el final. [Eusebio] era una criatura dramática y necesitaba el drama para vivir y para morir. Lo que no soportaba era la monotonía, la enfermedad, la vejez. Quiso enterarse de a qué hora iba (Manuelita) el viernes para darse en espectáculo dramático al ser amado...» ${ }^{50}$.

$$
\text { * * * }
$$

En conclusión, la crítica destaca el entusiasmo, disciplina y cohesión de la labor interpretativa del grupo, facilitados por la falta de divismo de

${ }^{47}$ GIBSON, Ian. Federico García Lorca. De Fuente Vaqueros a Nueva York (18981929). Madrid: Crítica, 1998, pp. 591-592. Según Ucelay (op. cit., p. 142). José Jiménez Rosado había actuado con la compañía 'Caracol' en el papel de uno de los ángeles de Orfeo.

${ }^{48}$ Otra de los las figuras centrales de la renovación teatral española de aquellos años (véase Anderson, op. cit.).

${ }^{49}$ CHACEL, Rosa. La sinrazón. Bilbao: Albia, 1977.

${ }^{50}$ Recogida en DORAO, op. cit., p. 224. Manuela Mur (Manuelita) era una estudiante argentina que sentía una admiración reverencial por Eusebio, al que ayudaba en su labor de traductor (Dorao, op. cit., p. 201). 
los actores que desempeñaron los papeles de protagonistas, aun en el caso de ser éstos, autores o actores profesionales. Otros rasgos que fueron igualmente resaltados dan prueba de la capacidad con la que el grupo interiorizó los presupuestos de un teatro nuevo frente a los excesos naturalistas: fidelidad al autor, renuncia al lucimiento, falta de amaneramientos interpretativos, supeditación al tratamiento escénico... De tal comportamiento parece deducirse una inteligente puesta en práctica de las consideraciones teóricas sobre las técnicas actorales defendidas por Rivas Cherif, director de la mayoría de las obras, y que pueden resumirse en el empeño de restablecer la preferencia del autor sobre el resto de los elementos del espectáculo.

La valoración de Rivas Cherif como actor abunda en dicha hipótesis. De acuerdo con los principios que defiende, los críticos destacan de sus creaciones interpretativas, además de su talento, el respeto a la intencionalidad del autor y a los propios personajes. Lejos de imitar a la vida en sus detalles nimios, compone personajes esquemáticos, trazados como pinceladas. Así, no es de extrañar que en el tratamiento interpretativo se muestre leve, ágil y versátil, rasgos que, por otra parte, servirían para definir a los personajes del guiñol.

No deja de causar cierta sorpresa que la crítica destaque de las interpretaciones de Gorbea su cercanía a los actores profesionales. Dejando aparte la voz y la dicción, otros rasgos que se resaltan, como carácter, tono, ademán, gesto, rudeza..., parecen ciertamente lejanos a los considerados ideales para encajar en estos ensayos de renovación teatral. Tampoco se relacionan con los que podrían pensarse más idóneos para representar un personaje como don Perlimplín, moviéndose al principio entre lo ridículo y lo guiñolesco. En cambio, parecen más propios del tipo de actuación, cercana al naturalismo, que se ajusta mejor a las obras que Gorbea escribía: drama rural, comedia tradicional, novela histórica de tono arcaizante... Lo cierto, es que fue el actor que recibió de los críticos los mayores elogios de todos los que participaron en estas iniciativas.

\section{REFERENCIAS BIBLIOGRÁFICAS}

AGUILERA SASTRE, Juan; AZNAR SOLER, Manuel. Cipriano de Rivas Cherif y el teatro español de su época (1891-1967). Madrid: Publicaciones de la Asociación de Directores de Escena de España, 1999.

ANDERSON, Andrew A. «Coincidencias y paralelismos: las carreras teatrales de Ricardo Baeza y Cipriano Rivas Cherif». Actas del XII Congreso de la Asociación Internacional de Hispanistas. Birmingham, 1995, pp. 41-49.

ANGULO EGEA, María. «De Moratín a Valle Inclán. Más de cien años de batalla teatral». Cuadernos dieciochistas, 2004, 5, pp. 189-202.

ARAQUISTAIN, Luis. La batalla teatral. Madrid: CIAP, 1930.

BAROJA, Pío. Obras Completas. Madrid: Biblioteca Nueva, 1949.

BAROJA NESSI, Carmen. «Desde el nido de 'El Mirlo blanco'». La Gaceta Literaria, 1927, n. ${ }^{\circ} 8$, p. 5. 
—. Recuerdos de una mujer de la generación del 98. Barcelona: Tusquets, 1998.

CARO BAROJA, Julio. Los Baroja. Madrid: Taurus, 1972.

CHACEL, Rosa. «Cocteau-Orfeo». Revista de Occidente, 1928, LXVI, pp. 389-392.

—. La sinrazón. Bilbao: Albia, 1977.

DORAO, Marisol. Los mil sueños de Elena Fortún. Cádiz: Universidad de Cádiz, 1999.

GIBSON, Ian. Federico García Lorca. De Fuente Vaqueros a Nueva York (1898-1929). Madrid: Crítica, 1998.

GIL FONBELLIDA, María del Carmen. «Federico García Lorca y Cipriano Rivas Cherif: Una experiencia renovadora en el teatro profesional (1920-1935)». Dicenda, 1999, 17, pp. 63-88.

GONZÁLEZ MARTEL, Juan Manuel. «La amistad de Alejandro Sawa y Ramón del ValleInclán en el archivo de los Sawa (1862-1984)». Madrygal, 2006, 9, pp. 73-84.

LAVAUD, Jean-Marie. «El nuevo edificio del Círculo de Bellas Artes y 'El Cántaro roto', de Valle-Inclán». Segismundo, 1975, 21-22, pp. 237-254.

MARTÍNEZ SIERRA, María. Gregorio y yo. Valencia: Pretextos, 2000.

PALENCIA, Isabel de. I Must have Liberty. Nueva York: Longmans Green \& Co., 1940.

REY FARALDOS, Gloria. «Pío Baroja y 'El Mirlo blanco'». Revista de Literatura, 1985, XLVII, 93, pp. 117-127.

RIVAS CHERIF, Cipriano de. «Divagación a la luz de las candilejas». La Pluma, agosto de 1920, n. $^{\circ} 3$, pp. 113-119.

—. «Más cosas de don Ramón». La Pluma, enero de 1923, n. ${ }^{\circ} 23$, pp. 90-96.

-. Retrato de un desconocido. Vida de Manuel Azaña. Barcelona: Grijalbo, 1980.

- Cómo hacer teatro: Apuntes de orientación profesional en las artes y oficios del teatro español. Valencia: Pretextos, 1991.

SÁNCHEZ-COLOMER, María Fernanda. Valle-Inclán orador. Tesis doctoral: Universidad Autónoma de Barcelona, 2002.

UCELAY, Margarita. «Introducción» a la edición crítica de Don Perlimplín con Belisa en el jardín de Federico García Lorca. Madrid: Cátedra, 1990.

VILCHES, María Francisca; DOUGHERTY, Dru. La escena madrileña entre 1926 y 1931. Madrid: Fundamentos, 1997.

Fecha de recepción: 24 de noviembre de 2008

Fecha de aceptación: 26 de mayo de 2009 
